\title{
Spatio-temporal Characteristics Of Corn Drought Disaster in Jilin based on Yearly Growth Stage Data
}

\author{
Qi Zhang', Juan Du ${ }^{2}$, Jiquan Zhang ${ }^{3}$ \\ 1 College of Applied Meteorology, Nanjing University of Information Science and Technology, \\ Nanjing 210044, China \\ 2 Cold and Arid Regions Environmental Engineering Research Institute, Lanzhou 730000, China \\ 3. School of Environment, Northeast Normal University, Changchun 130024, China
}

\section{基于玉米逐年发育期的吉林省干旱灾害时空分 析}

\author{
张琪 ${ }^{1}$, 杜娟 ${ }^{2}$, 张继权 ${ }^{3}$ \\ 1 南京信息工程大学应用气象学院, 南京 210044 , 中国 \\ 2 寒区早区环境与工程研究所, 兰州 730000 , 中国 \\ 3 东北师范大学环境学院, 长春 130024 , 中国
}

\begin{abstract}
Based on daily precipitation data, maize growth and yield data for the period 1981-2009 at 12 meteorological stations in Jilin. Then the Standardized Precipitation Index (SPI) and Mann-Kendall test were used to study the drought disaster during different growing period of corn. The results showed that the maize during the phase of tasseling and maturity tend to dry in Jilin. Drought happened more and more frequently, especially in northeast Jilin Province. Drought happen in stage of tasseling and maturity resulted in severe effects on maize yield. In every growth stage severe drought and extreme drought had more remarkable influences on maize yield than others. The present study provides some scientific technical guidelines for drought resistance of maize in Jilin Province.
\end{abstract}

Keywords: Jilin Province, corn, the Standardized Precipitation Index (SPI), spatial distribution, yield

\section{摘要}

基于 1981-2009 年吉林省 12 个气象站点日降 水量资料和逐年玉米发育期资料, 利用标准化
降水指数 SPI、Mann-Kenda11 检验等方法分析 玉米不同生育阶段干旱灾害发生的时空特征 及对玉米产量的影响。研究结果表明, 1981-2009 年吉林省玉米的抽雄一成熟期有明 显干旱化趋势; 近 30 年吉林省玉米各生育阶 段干旱发生越来越频繁, 特别是东北部地区; 玉米在抽雄一成熟阶段发生干旱会对产量造 成比较严重的影响, 特别是发生重旱和特旱时。 研究结果可为吉林省玉米抗旱避灾工作提供 科学的技术指导。

关键词: 吉林, 玉米, 标准化降水指数 (SPI), 时空分布, 产量

\section{1. 引言}

干旱灾害是全球普遍存在的自然灾害。全 球有 120 多个国家和地区每年遭受不同程度 的干旱胁迫, 干旱面积约占陆地总面积的 $35 \%^{[1]}$ 。作为世界上影响面最广、造成农业损 失最大的自然灾害, 干旱造成的经济损失远远 超过其他气象灾害, 据测算可高达 520 亿人民 $币^{[2-3]}$ 。据统计, 在自然灾害中气象灾害约占 十分之七, 而气象灾害中半数都是干旱灾害 ${ }^{[4]}$ 受海陆地形条件制约, 中国大部分地区位于东 亚季风区, 近年来社会经济不断发展, 但我国 干旱化趋势日益严重, 各地干旱频发, 严重的 干旱灾害发生周期缩短为 $2-3$ 年 ${ }^{[5]}$ 。

气候变暖背景下, 干旱对农业生产的影响 极为严重 ${ }^{[6]}$, 各行业都会受到未来 50 年气候 变化影响, 农业首当其冲 ${ }^{[7]}$ 。干旱最直接的后 
果是导致农作物减产、食物短缺, 若持续干旱 则会导致土壤退化、水资源匮乏, 严重制约可 持续发展 ${ }^{[8]}$ 。在过去的几十年里, 世界农业产 出急剧增长 ${ }^{[9]}$ 。产量增加主要是因为科技进步、 设备改善和投入增加, 例如化肥施用量增加 ${ }^{[10]}$ 然而气象灾害是引起产量改变的主要原因。旱 灾是影响农业产量且发生最为普遍的世界气 象灾害之一, 因而是世界粮食安全的决定性要 素 ${ }^{[11]}$ 。自 20 世纪 70 年代以来, 大范围的干早 观测表明干旱的强度、持续时长和影响范围均 变大, 许多地区, 由于气温升高和降水减少, 更利于干旱发生 ${ }^{[12]}$ 。多项研究表明气候变化将 增加干旱地区的干旱风险, 从而导致粮食安全 系统濒临崩溃, 尽管许多地区粮食安全系统已 不堪重负 ${ }^{[13-15]}$ 。

玉米是我国重要的粮食作物、饲料和工业 原料, 在我国的粮食产业中占有重要位置。吉 林省一半以上面积种植玉米, 是我国主要的玉 米生产基地之一, 中部的玉米带现已经成为中 国重要的商品粮基地, 同时也是世界三大黄金 玉米带之一。玉米产量占全省粮食产量的 $70 \%$, 占全国玉米总产的 $15 \%$ 。由于降水量时间分 配不均, 导致玉米生长季内降水与需水存在矛 盾, 使得中、西部地区玉米普遍存在春夏季干 旱现象。1801-1949 年间, 吉林省有 47 年发 生旱灾, 其中有 25 年发生大旱和特大旱。新 中国成立后至 2015 年间, 吉林省有 62 年发生 旱灾, 其中发生大旱和特大旱年份共计 15 年。 2014 年夏季吉林省由于降雨持续偏少, 平均 降水量比常年同期减少 $65 \%$, 导致吉林遭遇建 国以来最严重干旱, 造成 943.4 千公顷农作物 受灾, 绝收面积超过 60 千公顷, 直接经济损 失达 45 亿元。因此, 掌握干旱的变化趋势及 其分布规律是科学制定防旱避灾决策的先决 条件。

现有研究干旱与玉米产量关系的文献很 多, 均是先利用干旱指标确定干旱程度, 再研 究玉米种植区干旱的分布特征及其对产量的 影响, 并构建作物产量影响模型。这些研究一 般采用玉米发育期的多年平均值代表当地一 般发育期, 这样计算出来的干旱指数与实际早 涝情况未必相符。本文选用标准化降水指数 (SPI) 研究吉林省玉米不同生育阶段干旱变化 趋势、干旱时空分布特征及其对玉米产量的影 响, 确定玉米受干旱影响的关键生育阶段, 为 吉林省玉米的抗旱避灾工作提供技术指导。

\section{2. 资料与方法}

\section{1 研究区域概况}

本文的研究区域为吉林省, 位于东经 $121^{\circ} 38^{\prime} \sim 131^{\circ} 19^{\prime}$, 北纬 $40^{\circ} 50^{\prime} \sim 46^{\circ} 19^{\prime}$ （图 1), 属于温带大陆性季风气候, 四季分 明, 雨热同期。年平均降水量为 $400 \sim 600 \mathrm{~mm}$,
但有明显的地区和季节降水差异，降水 $80 \%$ 集 中在夏季, 东部降水最为充沛, 从东南向西北 形成了由湿润区到半湿润区再到半干旱区的 过渡。无霜期一般为 100 160d; 主要种植作 物为玉米, 作物种植模式为一年一熟。

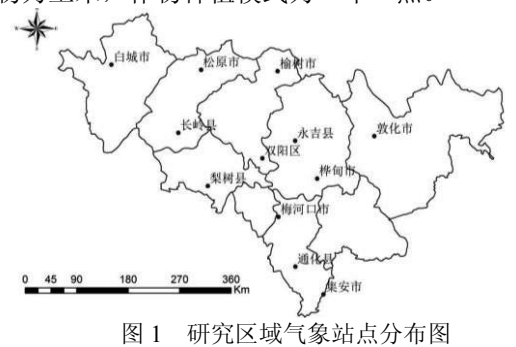

\section{2 数据来源}

\subsection{1 气象资料}

气象资料来源于中国气象数据网 (www. data. cma. cn), 包括研究地区 12 个气象 站点（图 1) 近 30 年逐日降水量数据。

\subsection{2 作物资料}

作物资料来源于中国气象局农业气象观 测站，包括玉米产量资料和玉米生育期资料。 产量资料包括玉米单产资料, 生育期资料包括 玉米播种日期、拔节日期、抽雄日期及成熟日 期。

\section{3 研究方法}

\section{3 .1 标准化降水指数 (SPI)}

SPI 是在计算出某时段内降水量的 $\Gamma$ 分 布概率后, 通过正态标准化处理用标准化降水 累积频率分布来划分干旱等级, 具体计算方法 见参考文献 ${ }^{[16]}$ 。基于指标描述干旱强度、范围 和起止时间的精确性、包含物理机制的明确性 以及应用的广泛性三个方面综合分析, SPI 的 优点一是计算过程只需要降水资料, 数据易于 获取; 优点二是计算过程中没有与降水量的时 空分布特性有关的参数, 能较好反映不同时空 的旱涝状况, 适合多空间、多尺度比较, 是分 析干旱演变趋势的理想指标。

本文选用 SPI 作为确定吉林省玉米生育 期干旱的识别指标，参考《气象干旱等级》 ${ }^{[17]}$ 划分 SPI 的干旱等级如表 1 所示:

表 1 标准化降水指数 (SPI) 干旱等级划分

\begin{tabular}{ccc}
\hline 干旱等级 & 类型 & $\mathrm{SPI}$ 值 \\
\hline 0 & 无旱 & $\mathrm{SPI}>-0.5$ \\
1 & 轻旱 & $-0.5 \geq \mathrm{SPI}>-1.0$ \\
2 & 中旱 & $-1.0 \geq \mathrm{SPI}>-1.5$ \\
3 & 重旱 & $-1.5 \geq \mathrm{SPI}>-2.0$ \\
4 & 特早 & $-2.0 \geq \mathrm{SPI}$ \\
\hline
\end{tabular}

2.3.2 Mann-Kenda11 趋势检验

气候变化及其响应的重要内容之一就是 
判断研究对象在一段时间内是否具有趋势变 化。Mann-Kendall 趋势检验是一种非参数趋 势检验, 其优点是不要求检验序列服从某种固 定分布, 且允许序列存在异常值或缺测值 [18]。 对时间序列数据（X1, X2, ․, Xn) 进行趋 势分析, 主要分为两步:

第一步, 计算检验统计量 S 如下式

$S=\sum_{i=2}^{n} \sum_{j=1}^{i-1} \operatorname{sign}(X i-X j)$

$\operatorname{sign}(X i-X j)=\left\{\begin{array}{c}+1, X i-X j>0 \\ 0, X i-X j=0 \\ -1, X i-X j<0\end{array}\right\}$

第二步, 根据统计量 $\mathrm{S}$ 的正负计算检验 量 Z 如下式

$Z=\left\{\begin{array}{cc}\frac{S-1}{\sqrt{n(n-1)(2 n+5) / 18}}, & S>0 \\ 0 & , S=0 \\ \frac{S+1}{\sqrt{n(n-1)(2 n+5) / 18}}, S<0\end{array}\right\}$

当 $Z>0$ 时表明时间序列有上升趋势, 当 $Z<0$ 时表明时间序列有下降趋势。当 $|Z| \geqslant 1.28$, 1.64 和 2.32 时, 表示该趋势分别通过了信度 为 $90 \%, 95 \%$ 和 $99 \%$ 的显著性检验 ${ }^{[19]}$ 。

对 12 个气象站点不同生育阶段的 SPI 序 列进行 Mann-Kendall 趋势检验, 判断各阶段 SPI 的变化趋势, 进而明确各站点玉米在不同 生育阶段的干湿变化趋势。

\section{3 结果与分析}

3.1 1981-2009 年吉林省玉米不同生育阶段干 湿变化趋势

对每个站点 3 个生育阶段的 SPI 序列进行 Mann-Kendall 趋势检验得到吉林省玉米不同 生育阶段的 SPI 变化趋势空间分布图(图 2)。 由图 2 可以看出, 播种一拔节期白城、敦化、 集安、梅河口、松原、榆树 6 个地区 Mann-Kenda11 统计量都为负值, 即 SPI 呈减 小趋势, 表明近 30 年该阶段呈现干旱化趋势。 长岭、桦甸、梨树、双阳、通化、永吉 6 个地 区 Mann-Kendall 统计量都大于 0 , 即 SPI 呈 增大趋势, 说明近 30 年这几个地区在该阶段 呈现增湿趋势, 但增湿趋势尚未通过显著性检 验。拔节一抽雄期除白城、双阳、集安、永吉 4 个地区外, 其他 8 个地区 Mann-Kenda11 统 计量都为负值, 长岭县、松原市干旱化趋势显 著 $(P<0.05)$, 梅河口市干旱化趋势达显著水 平 $(P<0.1)$ 。抽雄一成熟期双阳和松原 2 个 地区呈增湿趋势, 但未通过显著性检验, 此外 吉林省大部站点干旱化趋势明显, 其中白城市、 长岭县、敦化市、桦甸市、梨树县干旱化趋势 达显著水平 $(P<0.05)$ 。

从玉米生育期的整个发展进程来看, 近 30 年玉米从生育阶段 1 到生育阶段 3 , 干旱化 趋势的站点逐渐增多, 干旱范围逐渐扩大。抽 雄一成熟期全省超过四分之三的区域有变干趋 势, 东部和西部干旱化强度最大, 说明吉林省 玉米在抽雄一成熟期更易发生大面积干旱。

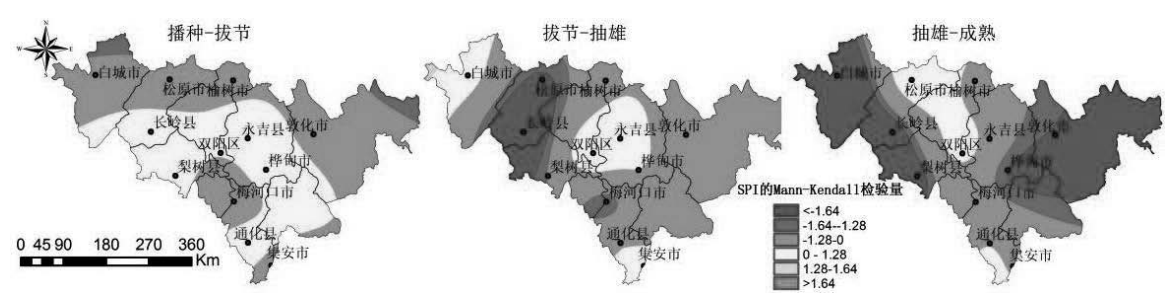

图 2 吉林省玉米生育期内不同生育阶段标准化降水指数变化趋势

本文研究吉林省干旱随时间变化规律时, 将时间序列分为 80 年代 (80s)、90 年代 (90s) 和 21 世纪初期 $(00 \mathrm{~s})$, 根据干旱分级标准, 分别计算各个年代各个站点不同生育阶段干 旱的发生频率 $\mathrm{F}$, 即干旱发生的年份 $\mathrm{n}$ 与总年 数 $\mathrm{N}$ 的比值, 即 $F=\frac{n}{N}$ 。播种一拔节期, 80 年代吉林省全省平均干旱频率为 $0.33,90$ 年 代为 $0.23,21$ 世纪初期为 0.35 , 干旱频率随 年代变化先减小后增大。拔节一抽雄期, 80 年代吉林省全省平均干旱频率为 $0.21,90$ 年 代为 $0.31,21$ 世纪初期为 0.35 , 随年代变迁
干旱频率逐渐增大。抽雄-成熟期, 80 年代吉 林省全省平均干旱频率为 $0.34,90$ 年代减小 为 $0.26,21$ 世纪初期增大达到 0.42 。可以看 出总体上玉米生育期干旱灾害随时间有逐渐 增加的趋势。

图 3 给出吉林省玉米不同生育阶段不同 年代的干旱频率空间分布。图 3(a) 为播种 到拔节期, 可以看出 80s 干旱发生频率在吉林 省东南部和西部较高, 在 $90 \mathrm{~s}$ 干旱在北部频率 较高, 00s 在西北部和南部地区较高。图 3(b) 为拔节到抽雄期, 由图可知 $80 \mathrm{~s}$ 干旱发生频率 在吉林省中部偏北地区较高, 在 $90 \mathrm{~s}$ 干旱在东 
北部频率较高, $00 \mathrm{~s}$ 在西北部和南部地区较高。 图 3(c) 为抽雄到成熟期, 展现出 $80 \mathrm{~s}$ 吉林 省中部地区为干旱频率高值区，90s 干旱发生 频率在东北地区较高, 在 $00 \mathrm{~s}$ 东北部和西部干 旱频率较高。

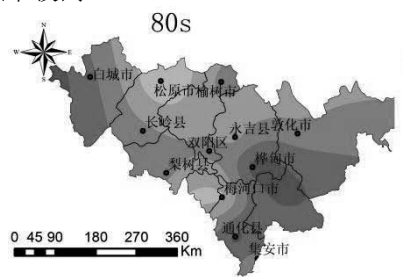

$80 \mathrm{~s}$

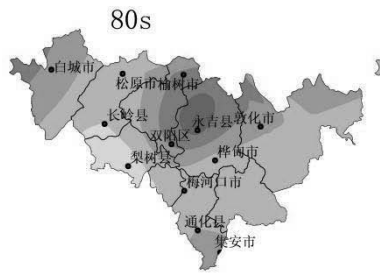

$90 \mathrm{~s}$
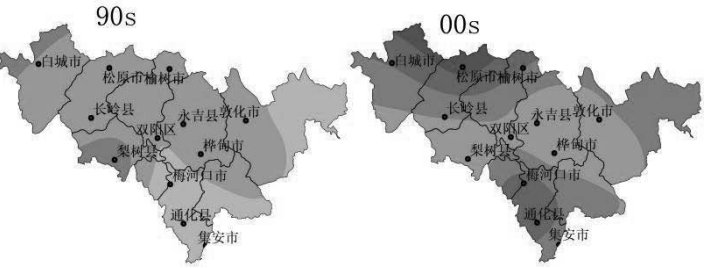

. 播种一拔节

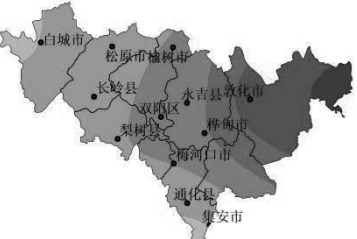

b. 拔节一抽雄

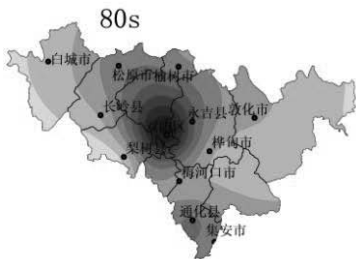

$90 \mathrm{~s}$
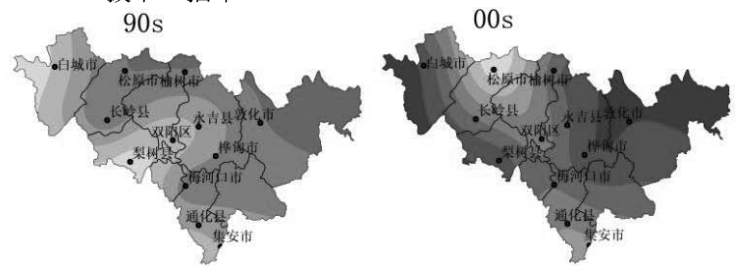

干旱频率

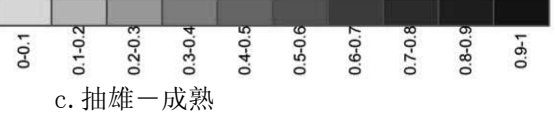

图 3 吉林省玉米不同生育阶段不同年代干旱频率空间分布图

\section{2 吉林省干早对玉米产量的影响}

根据吉林省玉米单产资料, 使用曲线回归 方法拟合各站点实际产量 Y 随年份变化的曲 线方程, 得到趋势产量 $Y_{t}$, 分离提取气象产 量 $Y_{w}$ 并计算各站点减产率 $Y_{r}$ 。 $Y_{r i}=\frac{-Y_{w i}}{Y_{t i}} \times 100 \%$, 其中 $i$ 表示年份。减产率 大于 0 , 表明该年有气象灾害发生,产量减少; 减产率小于 0 , 表明该年气象因子有利于作物 生长, 产量增加。通过统计各站点不同生育阶 段 4 个干旱等级作用下的多年减产率来确定 各等级干旱对玉米产量的影响程度。

图 4 展示了玉米在不同生育阶段发生轻 旱、中旱、重旱、特旱时造成的减产率。在播 种一拔节阶段, 轻、中、重、特 4 个等级早造 成玉米减产率的多年平均值分别 $3.03 \% 、 1.93 \%$ 、 $11.40 \% 、 14.93 \%$; 造成减产率的四分位距分别
为 $21.84 \% 、 31.06 \% 、 36.87 \% 、 23.66 \%$, 四分 位距越大, 表明数值分散越离散。拔节一抽雄 阶段， 4 个等级干旱造成玉米减产率的多年平 均值为分别轻旱 $1.09 \%$ 、中旱 $-8.05 \%$ 、重旱 $0.42 \%$ 、特旱 $15.73 \%$; 各等级干旱造成减产率 的四分位距分别为 $27.83 \% 、 19.67 \% 、 6.85 \%$ 、 $52.31 \%$ 。抽雄一成熟阶段, 各等级干旱对玉米 产量的减产率随着干旱程度的加重呈增加趋 势，4 个等级干旱造成玉米减产率的多年平均 值为轻旱- $1.53 \%$ 、中旱 $4.52 \%$ 、重旱 $12.76 \%$ 、 特旱 $17.83 \%$; 各等级干旱造成减产率的四分 位距分别为 $26.73 \%$ 、23. $02 \%$ 、34.67\%、37. $45 \%$ 。 总体可以看出, 各生育阶段轻旱和中旱对玉米 产量的影响明显小于重旱和特旱的影响, 抽雄 一成熟阶段的各等级干旱对玉米产量的影响 程度最大, 是对干旱响应的关键时期。播种一 拔节阶段次之, 拔节一抽雄阶段影响最小。 


\section{Risk Analysis and Crisis Response in Big Data Era (RAC-16)}

通过上述分析可以得出, 吉林省玉米抽雄 一成熟期阶段发生重早及以上程度干早对产 量造成的损失最大。下图是该阶段各站点发生 重旱及特旱时玉米平均减产率空间分布。由图 5 可以看出, 全省减产率的分布呈现西多东少, 北多南少的趋势。其中, 白城和榆树减产率最 大，超过 $30 \%$ 。减产率的分布规律表明由于吉 林省东部及南部位于湿润地区, 即使发生严重 干旱, 对玉米产量影响不大, 抗旱能力强。而 吉林省西部和北部地区玉米的抗旱能力弱, 玉 米产量对重、特旱的响应明显, 抽雄一成熟期 一旦发生干旱会对玉米产量带来明显的影响。

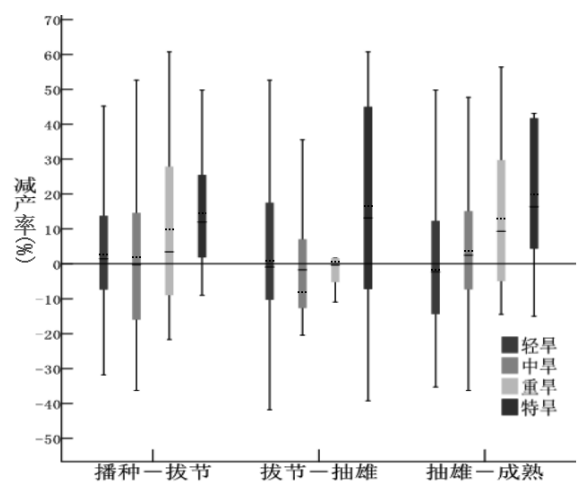

注: 直线为中值, 虚线为平均值。

图 4 吉林省不同等级干旱造成玉米产量的减 产率

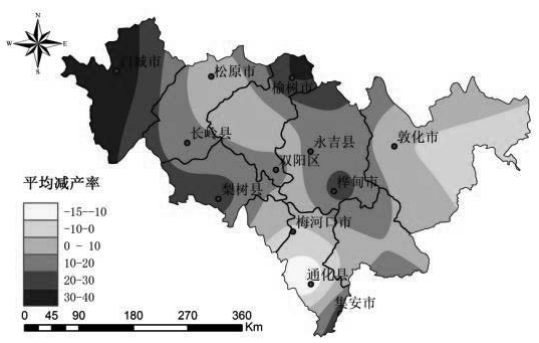

图 5 抽雄一成熟期吉林省重旱及特旱时 玉米平均减产率

\section{4. 结论与讨论}

本文选用 SPI 作为吉林省玉米不同生育 阶段干旱识别指标, 分析了吉林省干旱变化时 空分布规律及吉林省干旱对玉米产量的影响。 主要结论如下:（1）播种一拔节期吉林中部、 南部增湿化趋势明显, 后 2 个生育阶段吉林省 大部呈现干旱化趋势, 抽雄一成熟期全省超过 四分之三的区域有变干趋势, 东部和西部干旱 化强度最大, 说明吉林省玉米在抽雄一成熟期 更易发生大面积干旱。(2) 玉米播种一拔节期 干旱频率低, 高频干旱区域面积小, 抽雄一成
熟期干旱发生频率最高; 玉米各生育阶段的干 旱频率随着年代推移而增大。(3) 吉林省西部 和北部地区玉米的抗旱能力弱, 东部及南部抗 旱能力强。玉米抽雄一成熟阶段发生干旱造成 产量损失最为严重, 且该阶段数据的离散程度 最大, 各等级干旱造成的平均减产率为特旱 $17.83 \%>$ 重早 $12.76 \%>$ 中早 $4.52 \%>$ 轻早 $-1.53 \%$; 造成减产率的四分位距分别为轻早 (26.73\%)、中旱 $(23.02 \%)$ 、重旱 $(34.67 \%)$ 、 特旱 $(37.45 \%)$ 。不同等级干旱中重旱和特旱 对产量的影响明显高于轻早和中早。

本文划分玉米生育时期时不同于现有研 究以月为时间节点, 并采用发育期的多年平均 值代表当地一般发育期, 而是以不同地区每年 实际生育期资料进行划分, 使得计算出来的 SPI 更准确。这是本文的主要创新点。

本研究由于各项条件限制尚存在一些不 足之处。首先, 未进行 SPI 在吉林省的本地化 修正。地理状况和气候特点的差异使得同一气 象指标在不同地区阈值有所不同 ${ }^{[20]}$, 直接使用 《气象干旱等级》 ${ }^{[17]}$ 对 SPI 的划分标准划分吉 林省干旱等级存在一定的偏差。其次, 本文趋 势产量拟合是简单的将趋势产量看作是时间 序列的曲线函数, 但这种方法适用于单产波动 不明显的情况。研究站点中集安直接拟合曲线 效果不好, 降低了整体有关减产率的信度。最 后, 本研究没有考虑在过去近 30 年中玉米品 种的更替, 也没有考虑其它气象灾害可能造成 的玉米减产率。这些不足将是以后研究工作中 需改进和注意的地方。

\section{致谢}

本文以国家自然科学基金青年基金项目

(41501553)、江苏省科技厅基础研究计划青 年项目 (BK20150898)、南京信息工程大学人 才启动经费项目 (2014r052) 为项目支撑。

\section{参考文献}

[1] 司东, 李修仓, 任福民, 等. 2011 年全球重 大天气气候事件及其成因. 气象, 2012, 38(4):480-489.

[2] 闵娜, 杜继稳, 李登科, 等. 干早遥感监测 方法研究应用进展。灾害学, 2008, 23(4):117-121.

[3] Wilhite D A. Drought as a natural hazard : Concepts and definitions. Drought A Global Assessment, 2000, 1:3-18.

[4] 刘颖秋. 干旱灾害对我国社会经济影响研 究. 北京: 中国水利水电出版社, 2005:2-4.

[5] 王利娜, 苏静, 郑晓东, 等. 我国农业干旱 风险研究进展简述. 水科学与工程技术, 2011, 2:3-7.

[6] Zhang Q, Gao G. The spatial and temporal 
features of drought and flood disasters in the past 50 years and monitoring and warning services in China. Science \& Technology Review, 2004, 7:21-24.

[7] Da Q, Yi D, Shao W, et al. Ecological and environmental change in west China and its response strategy. Advance in Earth Sciences, 2002, 17(3):314-319.

[8] 商彦荵. 农业旱灾研究进展. 地理与地理 信息科学, 2004, 20(4):101-105.

[9] FAO. The state of food and agriculture 2000: lessons from the past 50 years.. State of Food \& Agriculture Lessons from the Past Years, 2000, 79(5):410.

[10] Sheng G, Lin X, Xiao B, et al. Growth, inequality, and poverty, in rural China: The role of public investments. Eptd Discussion Papers, 2002, 55(125):417-419.

[11] Tubiello F N, Soussana J F, Howden S M. Climate Change and Food Security Special Feature: Crop and pasture response to climate change. Proceedings of the National Academy of Science, 2007, 104: 1968619690.

[12] Barker T, Bashmakov I, Bernstein L, et al. Summary for Policymakers IPCC Fourth Assessment Report, WorkingGroup III[C]// 9th Session of Working Group III of the IPCC. Thailand: Bangkik, 2007:12-19.

[13] Rosegrant M W, Cline S A. Global food security: challenges and policies. Science, 2003, 302(5652):1917-1919.

[14] Ericksen P J. Conceptualizing food systems for global environmental change research. Global Environmental Change, 2008, 18(1):234-245.

[15] He Y. Assessment research of Bijie drought risk based on cloud model. Journal of Risk Analysis and Crisis Response, 2013, 3(4): 192-200.

[16] 陶新娥，陈华，许崇育. 基于 SPI/SPEI 指 数的汉江流域 1961 2014 年干旱变化特 征分析. 水资源研究, 2015, 10(5)：404415.

[17] 国家气候中心. GB/T20481-2006 气象干 旱等级. 北京:中国标准出版社, 2006.

[18] 章诞武，丛振涛，倪广恒. 基于中国气象 资料的趋势检验方法对比分析. 水科学 进展, 2013, 24(4):17-25.

[19] 刘彦平, 蔡焕杰. 基于标准化降水指数 SPI 的泾惠渠灌区干旱演变对冬小麦气候 产量的影响. 干旱地区农业研究, 2015, 33(3):267-272.

[20] 谢五三，田红. 五种干旱指标在安徽省应 用研究. 气象, 2011, 37(4):503-507. 